\title{
Comment 11.2
}

\author{
SI KYONG SUNG
}

In 2000, Korea established the Technology Transfer and Commercialization Promotion Act, a Korean Bayh-Dole Act, and the ownership of public research results became able to be transferred to universities and public research institutes. The next year, the ownership of public research results was transferred to universities and public research institutes in compliance with the new regulation on the management of government-funded R\&D projects.

In the last five years, there have been three major blockbuster public knowledge transfers in Korea. In this chapter, these cases are introduced, along with the detailed concerns of the Korean Intellectual Property Office.

The first was the case in which a startup established by a public research organization grew successfully and a large amount of inventor compensation (more than USD 10 million) was awarded to each of two researchers. The Korean Bayh-Dole Act and the regulation on the management of government-funded $\mathrm{R} \& \mathrm{D}$ projects both stipulate that public researchers must be compensated for more than 50 percent of the royalty income of their research products. This case gave rise to the argument to alleviate the compensation gap between researchers. As a result, the government introduced a regulation to reduce the percentage of inventor compensation for the royalty gradually if the compensation exceeds USD 2 million a year.

The second case is one in which a university gave up filing a patent application for an invention (Bulk fin-FET), where the professor filed a patent application in United States of America (U.S.) in his own name and with his own money, and, ten to fifteen years later, received USD 10 million and USD 400 million royalty from foreign and Korean companies, respectively. In Korea, the market size is about one-tenth smaller than that of the U.S., and the compensation for patent infringement is as low as one-hundredth of the U.S compensation. Therefore, inventions that only 
have a Korean patent cannot make a good license contract. Unlike the BayhDole Act and the German employee invention law, the Korean Act did not stipulate the return of ownership to the inventor when the university gave up filing or sustaining a patent application. Therefore, academic inventions are often left idle unless the university applies for overseas patents. For reference, Korean universities file patent applications in foreign countries for only 4.5 percent of their domestic patent applications.

The third case is where a professor transferred his invention (CRISPR genetic scissors) to his own startup three days after disclosing it to his university, using a cheap upfront payment (about USD 20,000) and appropriate running royalty rate, and the company grew to about USD $\$ 800$ million in value last year. Since public technology in Korea can be transferred exclusively only when there is no demand for a nonexclusive license, the professor and the KTO are being accused of concealing the valuable patent and selling it off to the company concerned at a low price.

The reason for these problems is that ownership of public research results has been transferred institutionally to universities and public enterprises, but they are still regarded as public goods rather than private property. The purpose of ownership transfer in the Bayh-Dole Act is to ensure that the patents are widely used while public research organizations maximize their own profits. By the same token, the Korean BayhDole Act aims for public research results to be widely used but disapproves of a public research organization maximizing its profits. During the last fifty years of rapid economic growth, the purpose of public research in Korea was to help domestic companies to catch up quickly, and the research results were to be shared rather than be owned exclusively. Even after the establishment of the Korean Bayh-Dole Act, this perception has not changed, and Koreans still consider it unfair for someone to monopolize the profits from the results of tax-based research. It is clear that they do not want the invention to be returned to the inventor even if it is not going to be filed, and they consider it to be monopolization for a patent to be assigned to a startup and make a success.

We would like to add a few more details to the institutional incentives suggested by the authors of this chapter.

First, a patent should be recognized as the private property of the university and the public research institute. This means that the public research institute should be able to decide autonomously on the selection criteria for the company to transfer its results, the license type (exclusive/ nonexclusive), and the royalty distribution so that the public research 
institute can actively maximize its profits. When knowledge transfer can make money, universities and public research institutes, as well as researchers, will make efforts to get valuable patents and transfer technologies.

Second, the purpose of the knowledge transfer policy should be that the invention is used more rather than making the invention used by more companies. The ultimate goal of the patent system is to make more utilization of inventions in the long run, even if transitory monopolies are allowed. In fact, this is consistent with the public interest of public research policy, and is consistent with why researchers prefer knowledge sharing rather than knowledge transfer.

According to the second objective, it is better to choose a company that has the ability and willingness to commercialize the patent rather than the company that pays the highest upfront lump sum fee. Unfortunately, the running royalty income of Korean universities was only 8 percent of their total royalty incomes in 2017 , while that of the U.S. was as high as 55 percent. If universities and public research institutes are pushed to raise the immediate financial achievements with $R \& D$, they cannot but license their knowledge focusing on the upfront fee, regardless of commercialization.

There's no need to worry that SMEs and startups may have no opportunities if technologies are transferred institutionally to the companies that will utilize them more. Technologies transferred to large companies often go to the warehouse and lie dormant until a patent dispute arises. Rather, SMEs and startups are often eager to commercialize the patent for their survival. In particular, a company founded by the inventor him(her)self is very competitive in terms of technical expertise. If full authority over the profits is given to universities and public research institutes, they will make reasonable choices.

Although the purpose of public research policy may vary from country to country, the purpose behind granting ownership of research results to public research organizations must be the promotion of utilization of the results. For patent utilization, public research organizations pursuing profits are much better than bureaucracy. Policies that are applied to the knowledge transfer process should limit the private property rights of institutes only if they are clearly against the public interest. In the future, Korea intends to improve the system in this direction. 